\title{
ANÁLISE DOS MECANISMOS DE DEFESA DO EGO UTILIZADOS PELOS ETILISTAS E O IMPACTO DO VÍCIO NO MEIO SOCIAL
}

Analysis of ego defense mechanisms used by drinkers and the impact of addiction on social environment

Análisis de los mecanismos de defensa del ego utilizados por las bebidas y el impacto de la adicción en el entorno social

Joyce Francisca Carlos de Almeida ${ }^{1}$, Kelly Maria dos Santos Teixeira ${ }^{1}$, Patrícia Rodrigues Muniz $^{* 1}$, Érico Augusto Rosas de Vasconcelos ${ }^{2}$

${ }^{1}$ Graduanda do curso de Enfermagem, Centro Universitário Euro Americano - UNIEURO, Brasília, DF, Brasil.

${ }^{2}$ Docente do curso de Enfermagem, Centro Universitário Euro Americano - UNIEURO, Brasília, DF, Brasil.

*Correspondência: Centro Universitário Euro Americano - UNIEURO, Av. Castanheira, lote 3700, Águas Claras, Brasília-DF, Brasil.CEP:71.900-100.e-mail patriciarodrigues027@ gmail.com.

\section{Artigo recebido em 15/05/2020 aprovado em 03/09/2020 publicado em 05/03/2021.}

\section{RESUMO}

Desde a antiguidade as bebidas alcoólicas estiveram presentes no cotidiano de diversas culturas, já nos tempos modernos, seu uso nocivo tornou-se grave problema de saúde pública, gerando prejuízos físicos, psíquicos e sociais. O etilismo, classificado como síndrome de dependência, possui forte estigma social, em que geralmente o usuário tende a agir em defesa do seu consumo e nega a doença. O presente estudo tem como objetivo investigar os principais mecanismos de defesa do Ego utilizados pelos dependentes para alegar seu vício e os principais agravos sociais que afetaram sua vida devido à dependência. A coleta de dados deu-se por meio de formulário semiestruturado, realizado no Instituto Crescer Comunidade Terapêutica Nova Vida - DF, com indivíduos de idade igual ou superior a 18 anos. O estudo possibilitou identificar que entre os problemas sociais decorridos do abuso do álcool, a família foi a mais prejudicada. Em relação aos mecanismos de defesa do ego, foram identificados o uso dos mecanismos de negação, de projeção e de racionalização. Diante da proximidade com o problema apresentado, foi possível reconhecer a necessidade do aprimoramento de estratégias já existentes voltadas ao uso abusivo do álcool, visto que há ascendência de dependência junto à população mundial.

Palavras-chave: Alcoolismo; Mecanismos de Defesa; Problemas Sociais.

\section{ABSTRACT}

Since antiquity, alcoholic beverages have been present in the daily lives of several cultures, even in modern times, their harmful use has become a serious public health problem, generating physical, psychological and social losses. Alcoholism, classified as a dependency syndrome, has a strong social stigma, where the user generally tends to act in defense of their consumption and denies the disease. This study aims to investigate the main mechanisms of defense of the Ego used by addicts to claim their addiction and the main social problems that affected their life due to addiction. Data collection took place using a semi-structured form, carried out at the Crescer Comunidade Terapêtica Nova Vida Institute - DF, with individuals aged 18 years or over. The study made it possible to identify that among the social problems resulting from alcohol abuse, the family was the most affected. Regarding the mechanisms of defense of the ego, the use of mechanisms of denial, projection and rationalization were identified. In view of the proximity to the problem presented, it was possible to recognize the need to improve existing strategies aimed at the abusive use of alcohol, since there is an ascendancy of dependence among the world population.

Keywords: Alcoholism; Mechanism of Defense; Social Issues.

\section{RESUMEN}


Desde la antigüedad, las bebidas alcohólicas han estado presentes en la vida cotidiana de varias culturas, incluso en los tiempos modernos, su uso nocivo se ha convertido en un grave problema de salud pública, generando pérdidas físicas, psicológicas y sociales. El alcoholismo, clasificado como un síndrome de dependencia, tiene un fuerte estigma social, donde el usuario generalmente tiende a actuar en defensa de su consumo y niega la enfermedad. Este estudio tiene como objetivo investigar los principales mecanismos de defensa del Ego utilizados por los adictos para reclamar su adicción y los principales problemas sociales que afectaron su vida debido a la adicción. La recopilación de datos se realizó mediante un formulario semiestructurado, realizado en el Instituto Crescer Comunidade Terapêutica Nova Vida - DF, con personas de 18 años o más. El estudio permitió identificar que entre los problemas sociales resultantes del abuso del alcohol, la familia fue la más afectada. En cuanto a los mecanismos de defensa del ego, se identificó el uso de mecanismos de negación, proyección y racionalización. En vista de la proximidad al problema presentado, fue posible reconocer la necesidad de mejorar las estrategias existentes dirigidas al uso abusivo del alcohol, ya que existe una ascendencia de dependencia entre la población mundial.

Descriptores: Alcoholismo; Mecanismos de defensa; Problemas sociales.

\section{INTRODUÇÃO}

Ao longo da história é notável a utilização do álcool pela humanidade, seja de forma recreativa ou em ritos religiosos. O álcool apresentava um papel importante na formação das religiões, onde era utilizado em vários rituais religiosos. No entanto, o seu uso exagerado, reflete em um comprometimento de parte da população que pode desencadear problemas físicos e psíquicos (Zemel e Saddi, 2015).

O uso abusivo do álcool representa grave problema de saúde pública em todo o mundo, sendo um potencial gerador de altos custos para o sistema de saúde devido à mortalidade e às limitações funcionais causadas pelo seu uso (Monteiro et al., 2011). O risco de morte é inerente, como mostra os dados da World Health Organization (WHO, 2018), em que 3 milhões de pessoas morrem anualmente por conta do etilismo. Neste sentido, nas pesquisas em relação ao Brasil, o II Levantamento Nacional de Álcool e Drogas (Lenad) realizado em 2012, revela que o consumo regular de álcool pela população, caracterizado pela sua ingestão em uma ou mais vezes por semana, aumentou cerca de $20 \%$, em relação ao último estudo realizado em 2006, onde o total de adultos que bebiam regularmente era de $45 \%$ (Laranjeira et al., 2013).

Em nosso país o consumo de bebida alcoólica não só é permitido como também estimulado, isso devido à fácil aquisição, ao baixo custo e à presença das mais diversas variedades, atrelados a exploração e incentivo por meio da mídia. Dessa forma, ocorre uma imposição contra o combate ao etilismo, pois a apresentação da bebida alcoólica de forma atrativa pela mídia revela apenas as qualidades do produto, os quais são totalmente opostos à realidade (Silva et al., 2015). Conforme o Centro de Informações Sobre Saúde e 2 Álcool (CISA, 2019) o reconhecimento da doença pelos padrões de consumo, mostra-se bastante dificultado, devido à visão positiva acerca do álcool pela sociedade atual, o que reflete na ausência da mobilização precoce de profissionais da saúde para diminuir o índice de problemas decorrentes do uso do álcool.

Conforme a Organização Mundial da Saúde (OMS, 2010 in CISA, 2019), o etilismo também é visto pela Classificação Internacional de Doenças (CID-10) como síndrome de dependência, e definido como um conjunto de fenômenos fisiológicos, comportamentais e cognitivos que se desenvolvem após o uso repetitivo do álcool. A dependência se dá quando a pessoa não consegue mais controlar sua necessidade de beber e leva progressivamente à perda da liberdade de decisão sobre o quê e o quanto irá beber, passando assim, a ficar escravo de sua dependência (CISA, 2019). 
Conforme Jellinek (1952 in Townsend, 2017), há quatro fases pelas quais evolui o padrão do etilista, podendo haver variabilidade entre indivíduos. Na fase pré-alcoólica, o álcool é utilizado a fim de se obter alívio de tensões e estresse do dia a dia, já na fase alcoólica inicial, o álcool torna-se uma droga exigida pelo indivíduo; ele pode passar por curtos períodos de amnésia após ou até mesmo durante o consumo de bebida. O indivíduo que se encontra na fase crucial é controlado pela dependência, sendo que seu foco está centrado em beber. Por fim, na fase crônica, é raro encontrar o indivíduo sóbrio, pois a abstinência pode lhe causar terríveis sintomas e seu estado psicoemocional encontra-se altamente desintegrado.

Atualmente, o álcool tornou-se um dos principais fatores responsáveis por uma gama de problemas sociais. Conforme o Cisa (2019), seja no trabalho, no lar, no meio social, os danos resultantes são devastadores, e traz como consequências, muitas vezes, a violência e a pobreza. A ligação entre o desemprego e o consumo abusivo do álcool é evidenciada pela potencial redução da produtividade, sendo comuns altas taxas de acidentes de trabalho e absenteísmo. Já no contexto familiar, o etilismo traz inúmeros danos, afetando desde a saúde física e mental dos membros, até a saúde financeira do lar. Diante dessa realidade, com o objetivo de regular as ações referentes à diminuição dos danos sociais e à saúde decorrente do uso de drogas, foi criada a Portaria n. ${ }^{\circ}$ 1.028 , de $1^{\circ}$ de julho de 2005, que procura alcançar esse objetivo sem intervir obrigatoriamente na oferta ou no consumo (Brasil, 2005).

Mediante ao aumento do consumo de álcool pela população, fez-se necessário a descentralização de atendimento à saúde para maior abrangência as pessoas afetadas. Por meio da Portaria n. ${ }^{\circ} 336$, de fevereiro de 2002, instituiu a criação dos Centros de Atenção
Psicossocial (Caps), com serviço aberto e com a finalidade de uma atenção integral às pessoas (Brasil, 2002). O Caps é constituído por equipe multiprofissional que atua conforme a visão interdisciplinar, realizando atendimento aos indivíduos com transtornos mentais graves e persistentes, e às pessoas com necessidades decorrentes do uso de crack, álcool e outras drogas, seja em situações de crise ou nos processos de reabilitação psicossocial (Brasil, 2017).

Considerando a necessidade de intensificar, ampliar os atendimentos e diversificar as ações para prevenção, promoção da saúde e reduzir os riscos e danos relacionados ao consumo de crack, álcool e outras drogas, por meio da Portaria n. ${ }^{\circ} 130$, de janeiro de 2012, redefine o Centro de Atenção Psicossocial de Álcool e outras Drogas 24 horas (Caps AD III), onde prestará atendimento a um grupo populacional de 200 a 300 mil habitantes (Brasil, 2012). Em consonância ao exposto, a Portaria n. ${ }^{\circ} 3.588$, de 21 de dezembro de 125 2017, estabelece o Centro de Atenção Psicossocial de Álcool e outras Drogas do Tipo IV (Caps AD IV), sua implantação sendo planejada e seu atendimento se dará em municípios com mais de 500.000 habitantes e capitais de estado. O funcionamento dos Caps AD ocorre durante 24 horas/dia, todos os dias da semana, inclusive finais de semana e feriados. (Brasil, 2017).

$$
\text { Segundo Carvalho (2010), os Caps AD }
$$
trabalham prestando assistência especializada, possibilitando a atuação conjunta para atender indivíduos que fazem uso abusivo de álcool e/ou outras drogas, de forma integrada com a comunidade e vinculada a outros serviços assistenciais em saúde mental, como os ambulatórios, leitos hospitalares e hospitais-dia, além da rede básica de saúde. Também, articulam-se, a Estratégia de Saúde da Família (ESF) e Programa de Agentes Comunitários de Saúde (Eacs), entre outros. Deste modo, os Caps-AD buscam atender 
às várias necessidades dos usuários e aplicam os recursos terapêuticos para propiciar a reabilitação psicossocial e reinserção social das pessoas atendidas. Outra política pública importante e voltada diretamente para o contexto do uso abusivo do álcool é a Política Nacional sobre o Álcool. Aprovada pelo Decreto n. ${ }^{\circ}$ 6.117, de 22 de maio de 2007, essa política tem por objetivo sustentar medidas de enfretamento contra o uso abusivo do álcool, bem como os prejuízos atrelados a essa prática, que cada vez mais está relacionada com a criminalidade e a violência (Brasil, 2007).

Segundo Videbeck (2012), o desenvolvedor da teoria psicanalítica foi Sigmund Freud, no qual os comportamentos humanos são causados e podem ser explicados. Em sua conceituação, Freud explica que a estrutura da personalidade é formada por três componentes: o id, sempre em busca da gratificação imediata, causando comportamentos impensados e impulsivos, e até mesmo passando por cima de regras e convenções impostas pela sociedade. O superego, sendo o opositor do id, este, responsável por carregar os conceitos éticos e morais, valores e perspectivas que os pais e a sociedade esperam. A completar os componentes tem-se o Ego, considerado o mediador, o mantenedor do equilíbrio entre o id e o superego, pelo qual as pessoas desempenham um comportamento adequado, maduro e adaptativo junto à sociedade. Freud acreditava que o ego usava mecanismos de defesa como proteção ao indivíduo perante ameaças à integridade biológica ou psicológica, e que a maioria das pessoas que usam esses mecanismos precisa de ajuda para enxergar a realidade, de modo que elas não se dão conta do que estão fazendo, porque uma parte desses mecanismos opera no nível inconsciente da percepção.

Anna Freud (1953 in Townsend, 2017) identificou vários mecanismos de defesa utilizados pelo ego diante de uma ameaça à integridade biológica ou psicológica. Todos os mecanismos de defesa são usados, seja de modo consciente ou inconsciente, porém alguns mecanismos de defesa do ego são mais adaptativos que outros, pois são utilizados como mecanismo de proteção para o ego na tentativa de aliviar a ansiedade. Esses mecanismos se tornam malajustados quando empregados por uma pessoa até um grau em que interfira com a capacidade de enfrentar a realidade, nas relações interpessoais efetivas ou em sua atuação profissional. No momento em que esses mecanismos de defesa são usados mal-ajustados ocasionam a deterioração do ego.

Como a maioria dos diagnósticos mentais, o etilismo possui forte estigma social. No entanto, para a preservação da autoestima, a defesa natural utilizada pelos usuários acaba por trazer atrasos na intervenção terapêutica (Silva et al., 2015). O grande problema encontrado em relação aos dependentes, é que seu 126 pensamento lógico e a realidade dos fatos, bem como o juízo crítico, razão e bom senso, estão distorcidos, isso, devido a alterações em seus mecanismos de defesa (Nadvorny, 2006).

O presente estudo tem como objetivo investigar, por meio de relatos dos etilistas em tratamento, os principais mecanismos de defesa que eles utilizavam como justificativas para alegar sua dependência e quais agravos sociais impactaram negativamente na sua vida devido ao vício.

\section{MATERIAIS E MÉTODOS}

\section{Tipo de pesquisa e coleta de dados}

Trata-se de um estudo descritivo, que tem como abordagem o método qualiquantitativo. Para a evolução da pesquisa utilizou-se entrevista direcionada por meio de formulário, desenvolvido pelos pesquisadores, com perguntas objetivas e subjetivas a 
respeito dos principais problemas sociais que afetam os indivíduos etilistas, bem como os principais mecanismos de defesa do ego utilizados como proteção ou justificativa para o consumo de bebida alcoólica.

O instrumento é composto por dois eixos: o primeiro trata-se de quais problemas sociais foram mais significativos na vida pessoal dos indivíduos em tratamento $\mathrm{e}$ as principais situações ocorridas referentes a cada problema, conforme questões de múltipla escolha apresentadas. O segundo eixo teve como propósito, por intermédio de uma pergunta objetiva e as demais subjetivas, a identificação dos principais mecanismos de defesa que os dependentes alcoólicos utilizavam para justificar suas atitudes e vício, como também identificar a presença ou ausência do mecanismo de negação.

A coleta de dados ocorreu no mês de novembro de 2019, na Unidade II Instituto Crescer Comunidade Terapêutica Nova Vida, com sua sede localizada na cidade satélite Vicente Pires-DF, esta por sua vez, trabalha com institucionalização de dependentes químicos. Dos 73 internados, 45 indivíduos participaram da pesquisa. Foram considerados, conforme os critérios de inclusão, aqueles que concordaram em participar do estudo e assinaram previamente o Termo de Consentimento Livre Esclarecido (TCLE), indivíduos com idade maior ou igual a 18 anos e que estavam em tratamento contínuo a mais de 30 dias. Indivíduos internados devido à dependência somente de drogas ilícitas e os que apresentavam problemas mentais, agressividade ou instabilidade devido à abstinência, foram excluídos do estudo.

Todos os indivíduos da amostra eram do sexo masculino, sendo a média de idade de 37 anos. Dos excluídos da pesquisa, 1 era menor de idade, 9 encontravam-se em tratamento de outras dependências químicas, 11 possuíam menos de um mês de internação e 7 recusaram a participação na pesquisa.

A pesquisa foi executada com os participantes em períodos e horários disponibilizados pela instituição, a fim de que ela não interferisse nas atividades diárias do participante e da instituição.

\section{Análise de dados}

Foi realizada a análise quantitativa dos dados, por meio do aplicativo Microsoft office Excel 2013.

Para análise dos dados qualitativos, foi utilizada a análise temática, que segundo Minayo (2007), este método permite identificar, analisar, interpretar e relatar núcleos de sentidos, em que a sua presença ou constância possa indicar algo para os objetos analíticos utilizados. A análise temática é sistematizada em três etapas: a pré-análise, que consiste na seleção de documentos a fim de se analisar e elaborar indicadores que possam orientar a 127 interpretação final; na exploração do material, com o intuito de compreensão do texto, faz-se a transformação dos dados brutos, sendo feita a escolha das categorias teóricas que conduzirão a discussão dos temas; o tratamento dos resultados obtidos e a interpretação levam à análise estatística dos dados brutos para que seja feita inferências e interpretações de acordo com o referencial teórico utilizado no estudo.

\section{Aspectos éticos}

$\mathrm{O}$ projeto de pesquisa referente ao presente estudo foi previamente submetido ao Comitê de Ética e Pesquisa do Centro Universitário Euro-Americano (CEP/Unieuro), onde obteve sua aprovação com o número do parecer 3.697.685. Em todas as etapas da pesquisa preservou o sigilo, sendo assegurada a confidencialidade da identidade dos participantes, respeitando os preceitos estabelecidos de acordo com a 
Resolução n. ${ }^{\circ} 466 / 2012$, que deliberou sobre pesquisa com seres humanos. Os pesquisadores mantiveram o respeito, a dignidade e a autonomia dos entrevistados em participarem ou não da pesquisa, podendo desistir a qualquer momento, os quais tiveram a garantia do anonimato. Aqueles que aceitaram participar da entrevista e colaboraram com o estudo, assinaram e receberam o TCLE.

\section{RESULTADOS E DISCUSSÃO}

\section{Problemas sociais decorrentes do alcoolismo}

Mediante a realização das entrevistas com os dependentes alcoólicos, no primeiro momento foi abordado os problemas sociais mais significativos aos entrevistados decorrentes da utilização de bebidas alcoólicas de forma prejudicial. Abordaram-se as temáticas: família, trabalho, pobreza, violência e violência no trânsito. Dessa forma, buscou-se por meio de perguntas objetivas e de livre escolha, a opção de marcar mais de uma alternativa.

$\mathrm{Na}$ análise quantitativa dos dados obtidos ao citado anteriormente, os prejuízos relacionados à família, entre os demais problemas, foi o que obteve maior valor de respostas, seguido do trabalho com a diferença de apenas uma resposta. O problema social pobreza encontra-se na terceira posição, seguido dos problemas sociais relacionados à violência e à violência no trânsito, os quais obtiveram o mesmo quantitativo.

Ainda nesta questão, 7 indivíduos referiram-se a outros problemas ocorridos, e na opção não considero não se obteve nenhuma resposta. Esses resultados são melhor compreendidos no gráfico 1.

Gráfico 1. Problemas sociais decorrentes do etilismo mais significativos para o dependente.

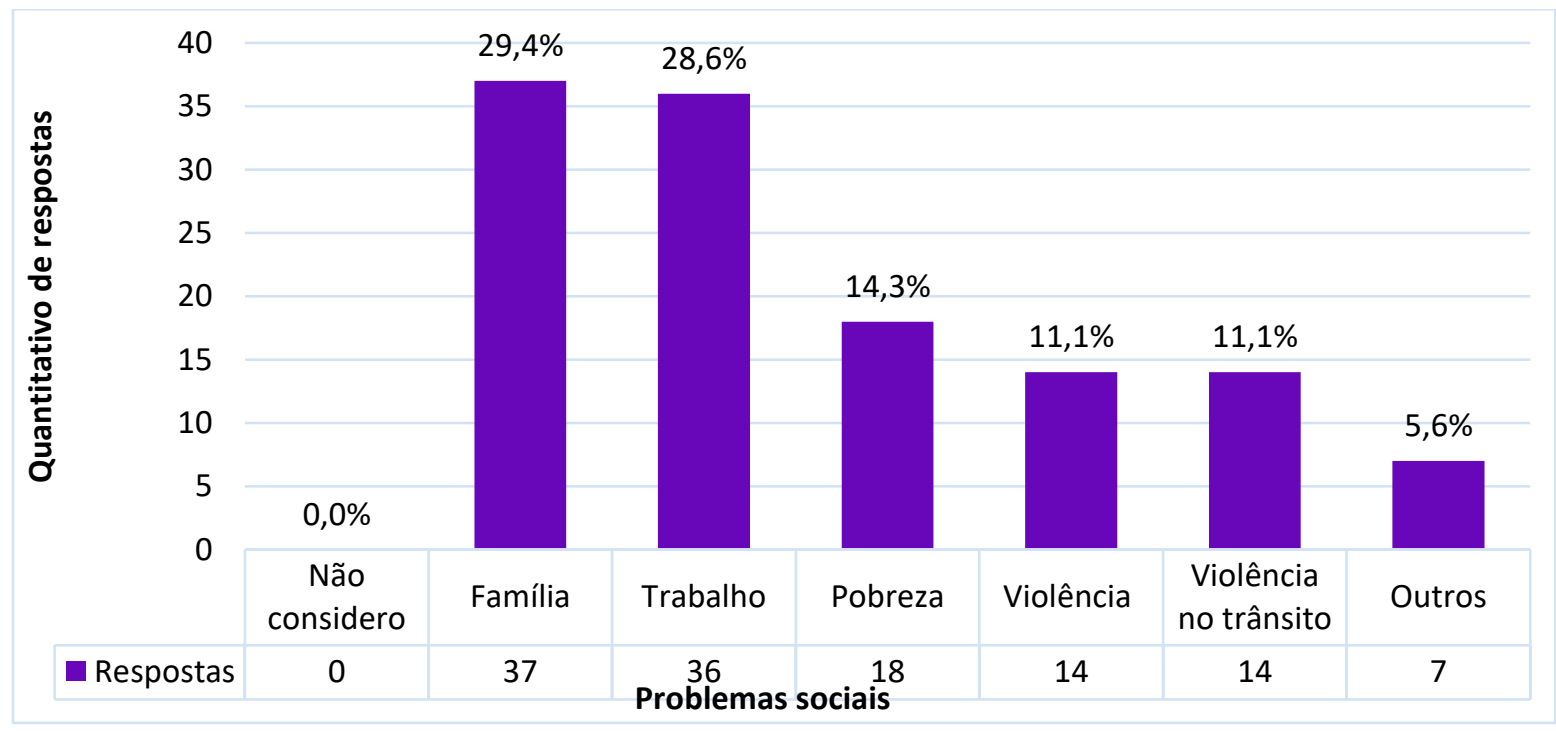

Nota-se que há uma predominância no tópico família $(29,4 \%)$, constando apenas a diferença de 1 resposta para o tópico trabalho, a seguir os itens violência e violência no trânsito apresentam o mesmo quantitativo, resultando ao todo em $22,2 \%$ do total das respostas. $\mathrm{O}$ etilismo por ser um potencial gerador de prejuízos sociais é considerado um problema de saúde pública, sendo então fator que merece atenção, como exposto por Reinaldo e Pillon (2008). Conforme Melo e Cavalcante (2019) a dependência alcoólica está inteiramente ligada a prejuízos à saúde, problemas familiares, sociais, financeiros e laborais. 
Ao observar os dados colhidos, constata-se que dentro das opções, a temática família e trabalho, foram quantitativamente mais evidentes nesta população. Os resultados obtidos podem ser comparados ao que é proposto por Felippe (2015), em que retrata que os problemas provenientes do álcool não se limitam somente aos que ingerem, mas a todos os que estão à sua volta, indo desde os familiares até ao ambiente de trabalho. Constata-se que mediante as afirmações citadas anteriormente e os resultados obtidos, o ambiente social em que o dependente alcoólico está inserido torna-se absorvedor das consequências advindas do álcool.

Ao proceder com o estudo, as demais questões envolveram as situações referentes a cada problema social, a fim de destrinchá-los para melhor compreensão da associação do alcoolismo com os prejuízos sociais. Dessa forma, o entrevistado teve a opção de escolher mais de uma alternativa nas questões, os resultados estão expostos na tabela 1.

Tabela 1: Situações ocorridas de acordo com cada problema social.

\begin{tabular}{lc}
\hline 1. FAMÍLIA & Total (\%) \\
\hline 1.1 Não considero & $3,9 \%$ \\
1.2 Conflitos familiar/extrafamiliar & $24,3 \%$ \\
1.3 Afastamento dos parentes e/ou amigos & $23,3 \%$ \\
1.4 Necessidade de abandonar família/amigos & $17,5 \%$ \\
1.5 Sentimento de vergonha por parte dos familiares & $27,2 \%$ \\
1.6 Outros & $3,9 \%$ \\
\hline 2. TRABALHO & Total (\%) \\
\hline 2.1 Não considero & $3,1 \%$ \\
2.2 Faltar o trabalho & $27,6 \%$ \\
2.3 Consumir álcool durante o serviço & $21,4 \%$ \\
2.4 Demissão devido ao vício & $16,3 \%$ \\
2.5 Perda de oportunidades de trabalho devido à dependência & $28,6 \%$ \\
2.6 Outros & $3,1 \%$ \\
\hline 3. POBREZA & Total (\%) \\
\hline 3.1 Não considero & $24,6 \%$ \\
3.2 Falta de dinheiro devido a gastos com bebidas & $23,1 \%$ \\
3.3 Dívidas adquiridas devido ao vício & $21,5 \%$ \\
3.4 Pedir ajuda financeira para cobrir despesas & $12,3 \%$ \\
3.5 Passar fome & $10,8 \%$ \\
3.6 Outros & $7,7 \%$ \\
\hline 4. VIOLẾNCIA & Total (\%) \\
\hline 4.1 Não considero & $21,7 \%$ \\
4.2 Dificuldade de controlar o comportamento & $22,9 \%$ \\
4.3 Cometer violência física no meio familiar/extrafamiliar & $16,9 \%$ \\
4.4 Partir para agressão verbal no meio familiar/extrafamiliar & $21,7 \%$ \\
4.5 Machucar a si próprio acidentalmente ou a alguém depois de usar álcool & $15,7 \%$ \\
4.6 Outros & $1,2 \%$ \\
\hline 5. VIOLÊNCIA NO TRÂNSITO & Total (\%) \\
\hline 5.1 Não considero & $28,8 \%$ \\
5.2 Dirigir sobre efeito do álcool & $25,8 \%$ \\
5.3 Preso ou multado por dirigir embriagado & $9,1 \%$ \\
5.4 Colocar em risco a vida de outras pessoas quando estava ao volante & $16,7 \%$ \\
embriagado & $16,7 \%$ \\
5.5 Causar acidente de trânsito após a ingestão de bebida alcóolica & $3,0 \%$ \\
5.6 Outros & \\
\hline & \\
\hline & \\
\hline
\end{tabular}

$\mathrm{Na}$ tentativa de compreender os principais agravos ocorridos no meio familiar/extrafamiliar, pôde-se constatar que nas alternativas sobre a ocorrência de episódios de sentimento de vergonha por 
parte dos familiares e sobre conflitos familiar/extrafamiliar, foram os tópicos que se sobressaíram aos demais. Pode-se fazer uma comparação ao que é proposto por Melo e Cavalcante (2019), ao evidenciar que a dependência alcoólica causa prejuízos, não somente ao usuário, mas a todos do meio social, trazendo em sua bagagem o sofrimento, o adoecimento, a vergonha, a raiva, a mudança de comportamento, bem como a crescente necessidade do afastamento social.

Apesar de a demissão ser uma consequência comum em indivíduos que cometem atos não tolerados pelo ambiente de trabalho, como o absenteísmo sem justificativa e o consumo de bebidas alcoólicas durante o expediente, observa-se que não é o que prevaleceu muito na pesquisa. $\mathrm{O}$ quantitativo de indivíduos que afirmaram consumir álcool durante o serviço e de faltar o trabalho devido ao vício, não é igual e nem menor ao quantitativo referente à demissão devido ao alcoolismo, sendo ainda, a situação referente ao trabalho com menos ocorrência em relação às demais. Esta questão pode ser explicada pela alteração nas leis trabalhistas, a partir do Projeto de Lei do Senado n. ${ }^{\circ}$ 83, de 2012, em que, o dependente alcoólico sendo um doente crônico, está resguardado da demissão, com a condição de que aceite se submeter a um tratamento para a sua recuperação (Brasil, 2012).

Apesar de a lei fornecer respaldo ao etilista contra a demissão, ela não trata da inclusão do dependente alcoólico no mercado de trabalho. Em conformidade a isso, percebemos diante dos dados que a situação mais comum referenciada pelos etilistas é em relação a perdas de oportunidades de trabalho. Como discutido por Silva e Luz (2015), a falta de emprego é uma situação comum para o indivíduo em questão. Associando os fatos, a perda de oportunidade de trabalho com os gastos elevados com bebidas gera dificuldade financeira que pode vir a resultar em pobreza, principalmente em regiões que já possuem altas taxas deste problema (CISA, 2019). Percebe-se nos dados, que na questão pobreza, as situações mais prevalentes foram em relação à falta de dinheiro e à aquisição de dívidas por conta de gastos com bebidas. Fica exposto que o sustento do vício acaba por gerar consequências econômicas expressivas, consistindo em um fator condicionante para a pobreza. Revela-se nesta amostra não ser incomum que o indivíduo chegue ao ponto de não ter dinheiro nem para se alimentar.

Segundo Araújo et al. (2018) em um aprofundamento dos estudos presentes na íntegra, existe uma correlação entre o uso de bebidas alcoólicas e a violência desde a antiguidade. $\mathrm{O}$ álcool em associação com o contexto no qual é inserido, as expectativas e atitudes do indivíduo, os valores sociais e os efeitos físicos e psicológicos decorrentes do uso da bebida alcoólica contribuem para o aparecimento de violências entre os relacionamentos interpessoais (Shahina et al. 2015 in Araújo et al. 2018). Mediante 130 ao exposto e a análise dos dados sobre a temática violência, verificou-se no total das repostas que a dificuldade em controlar o comportamento devido à dependência alcoólica, foi a situação considerada pelos dependentes como a mais ocorrida. Já o quantitativo relacionado a atos de agressão verbal, totalizaram o mesmo valor de respostas em relação à alternativa que indica não considerar o problema violência. Malbergier et al. (2009) ressalta que apesar de a ingestão do álcool conter certa relação com os comportamentos violentos e agressivos, existe sim, outros fatores relacionados ao consumo. Assim, é visto que o consumo do álcool em alguns casos está relacionado a atos de violência (CISA, 2019).

Diante de evidências em relação ao aumento da criminalidade e da violência, a Política Nacional sobre o Álcool traz princípios fundamentais para auxiliar estratégias de enfrentamento coletivo dos problemas relacionados ao consumo de álcool, 
abrangendo a intersetorialidade e a integralidade de ações para a redução dos danos sociais relacionados à saúde, à vida e a situações de violência e criminalidade associadas ao uso prejudicial de bebidas alcoólicas na população brasileira (Brasil, 2007).

O dirigir após beber é uma conduta preocupante em todo o mundo. Almeida (2014) referese que as principais causas de acidentes de trânsito são provocadas pelo consumo de álcool, sendo que suas consequências, muitas vezes, podem causar danos irreversíveis. Diante dos dados em relação à violência no trânsito, apesar de a maioria não ter considerado que a situação ocorreu, grande parte das respostas indicam a prática do dirigir após consumir bebida alcoólica, e o que revela a seriedade do problema é que alguns dos sujeitos da pesquisa já se envolveram em acidentes de trânsito após dirigir embriagado. No Brasil, cerca de 40 mil mortes por acidentes de trânsito foram evitadas com a implementação da Lei Seca, mas apesar disso, o problema ainda traz dados bastante preocupantes. Nos anos de 2010, 2016 e 2017, os acidentes de trânsito foram o segundo colocado entre as internações parcial ou totalmente atribuíveis ao álcool (CISA, 2019).

Outro ponto a se considerar é que há várias comorbidades associadas ao etilismo, como a depressão, por exemplo, que pode advir da soma entre o consumo abusivo do álcool e os problemas sociais gerados por essa prática. Segundo a Política Nacional sobre Drogas, aprovada pelo Decreto n. ${ }^{\circ}$ 9.761, de 11 de abril de 2019, a depressão entre os dependentes alcoólicos mostra-se com maior prevalência, sendo ainda que $24 \%$ das tentativas de autoextermínio no Brasil apresenta associação com o uso de álcool (Brasil, 2019).

Em síntese a isso, observa-se que o etilismo envolve não somente danos à saúde física por conta do uso nocivo do álcool, mas também sérios problemas sociais, resultando em prejuízos psicossociais ao dependente. $\mathrm{O}$ fator mais afetado dentre os problemas, foi à família, por estar diretamente ligada ao dependente, torna-se a principal prejudicada devido ao vício. Em seguida vem o trabalho, a pobreza, a violência e a violência no trânsito, todos eles gerando impactos negativos na sociedade em geral.

\section{Mecanismos de defesa do ego atrelados ao alcoolismo}

Segundo Videbeck (2012), Sigmund Freud desenvolveu a teoria psicanalítica, em que todo comportamento humano é causado e pode ser explicado. Os principais mecanismos evidenciados por Freud foram:

Compensação - Ter grandes sucessos em uma área para compensar deficiências reais ou percebidas em outra.

Conversão - Exprimir conflito emocional por meio do desenvolvimento de um sintoma físico, normalmente de natureza sensório-motora.

Negação - Ser incapaz de aceitar uma condição insuportável, de admitir a realidade de uma situação ou de permitir que o problema continue.

Deslocamento - Expor sentimentos intensos em relação a pessoas menos ameaçadoras do que aquela que originou esses sentimentos.

Dissociação - Lidar com um conflito emocional por meio de uma alteração temporária na consciência ou na identidade.

Fixação - Imobilizar uma porção da personalidade resultante da não conclusão de tarefas em certo estágio do desenvolvimento.

Identificação - Copiar o modelo de ações e opiniões de pessoas influentes, em busca de identidade ou por aspirar a concretização de um objetivo pessoal, social ou profissional.

Intelectualização - Separar as emoções e os fatos envolvidos em eventos ou situações dolorosas; aceitar os fatos, mas não as emoçõe. 
Introjeção - Aceitar atitudes, crenças e valores de outras pessoas como se fossem suas.

Projeção - Transferir, de maneira inconsciente, a um objeto externo a culpa por pensamentos ou inclinações próprias inaceitáveis.

Racionalização - Justificar o próprio comportamento para evitar culpa, responsabilidade, conflito, ansiedade ou perda de autorrespeito.

Formação reativa - Agir de modo oposto ao que pensa ou acredita.

Regressão - Retornar a um estágio de desenvolvimento anterior para se sentir seguro ou atender a necessidades.

Repressão - Excluir da consciência pensamentos e sentimentos emocionalmente dolorosos ou que provocam ansiedade.

Resistência - Antagonizar, de modo aberto ou encoberto, a lembrança ou o processamento de informações que produzem ansiedade.

Sublimação - Substituição de uma atividade de aceitação social por um impulso inaceitável.

Substituição - Substituição da gratificação desejada por outra mais rapidamente disponível.

Supressão - Exclusão consciente de pensamento e sentimentos inaceitáveis resultantes de percepção consciente.

Ato de desfazer - Manifestação de comportamento aceitável para compensar comportamento inaceitável ou para negá-lo.

Sendo para barrar as ameaças de ansiedade ou para preservar a autoestima, os mecanismos de defesa do ego encontram-se presentes em diversas situações com o propósito de manter o equilíbrio das instâncias psíquicas, podendo ser encontrados em qualquer indivíduo (Freud, 2006). Em contraste a isso, como forma de justificar um impulso considerado como inaceitável pela sociedade em geral e até mesmo negálo, o indivíduo com dependência alcoólica passa a externalizar esses mecanismos, para assim manter o seu comportamento, mascarando para si mesmo os riscos e os prejuízos ligados à prática do consumo abusivo do álcool (Towsend, 2017).

Segundo Ribadier e Varescon (2017), os mecanismos de defesa do ego agregam o conceito de enfrentamento como fator defensivo. Esses mecanismos são considerados como uma abordagem cognitiva e comportamental, deixando apenas de ser uma abordagem psicodinâmica. Os estilos de defesa neuróticos e psicopatológicos estão evidenciados em pessoas com dependência de álcool, verificando que há uma relativa estabilidade desses mecanismos. Estes indivíduos usam de preferência estratégias evitáveis e focadas na emoção.

Por meio do que foi evidenciado pelos autores sobre mecanismos de defesa, observa-se que os mecanismos de negação, de racionalização e de projeção são os que mais têm interligação com a dependência alcoólica. Esses mecanismos, quando alterados pelo etilismo, são utilizados pelos 132 dependentes com total convicção para defender suas argumentações, onde conseguem enganar o ego consciente da própria pessoa, passando assim a defender esse ego inconsciente como se fossem verdadeiros (Nadvorny, 2006).

Contudo, Filho et al. (2009), referem-se que na abordagem vygotskyana, nas relações que ocorrem em uma determinada cultura, o homem é visualizado como alguém que transforma e é transformado. Isso se dá pela interação, desde o nascimento, entre o ser humano e o meio social e cultural em que está inserido. Assim, do ponto de vista de Vygotsky o desenvolvimento humano ocorre por trocas recíprocas, não como a decorrência de fatores isolados que amadurecem, e nem tampouco de fatores ambientais que agem sobre o organismo controlando seu comportamento, essas trocas se estabelecem durante toda a vida, entre as pessoas e o meio, cada um influenciando sobre o outro. Também, demonstra que 
o homem deve ser compreendido na interação com o mundo à sua volta, interação essa que é mediada pelos objetos criados pelos próprios homens possibilitando o desenvolvimento das funções psicológicas.

Diante das afirmativas sobre mecanismos de defesa, observa-se que os autores citados conseguem definir de formas diferentes sobre o comportamento humano. Tanto pode existir uma relação do comportamento do etilista com mecanismos de defesa, quanto estar relacionado com a influência sobre o indivíduo do meio em que vive.
O conhecimento da estrutura da personalidade pode ajudar quem trabalha nas unidades que tratam os dependentes, pois a habilidade de identificar os comportamentos associados ao id, ego e ao superego ajudará na compreensão do nível de desenvolvimento, além da importância para determinar sobre comportamentos mal-ajustados, assim levando a um planejamento dos cuidados a pessoa para ajudá-la a criar mudanças, ou até mesmo a se aceitarem como indivíduos que necessitam de auxílio (Townsend, 2017).

Gráfico 2. Mecanismos de defesa do ego identificados a partir da questão objetiva acerca de exemplos de justificativas mais utilizadas pelo alcoólatra, e pelas questões subjetivas quanto aos motivos que o levou ao vício e em relação à aceitação da doença.

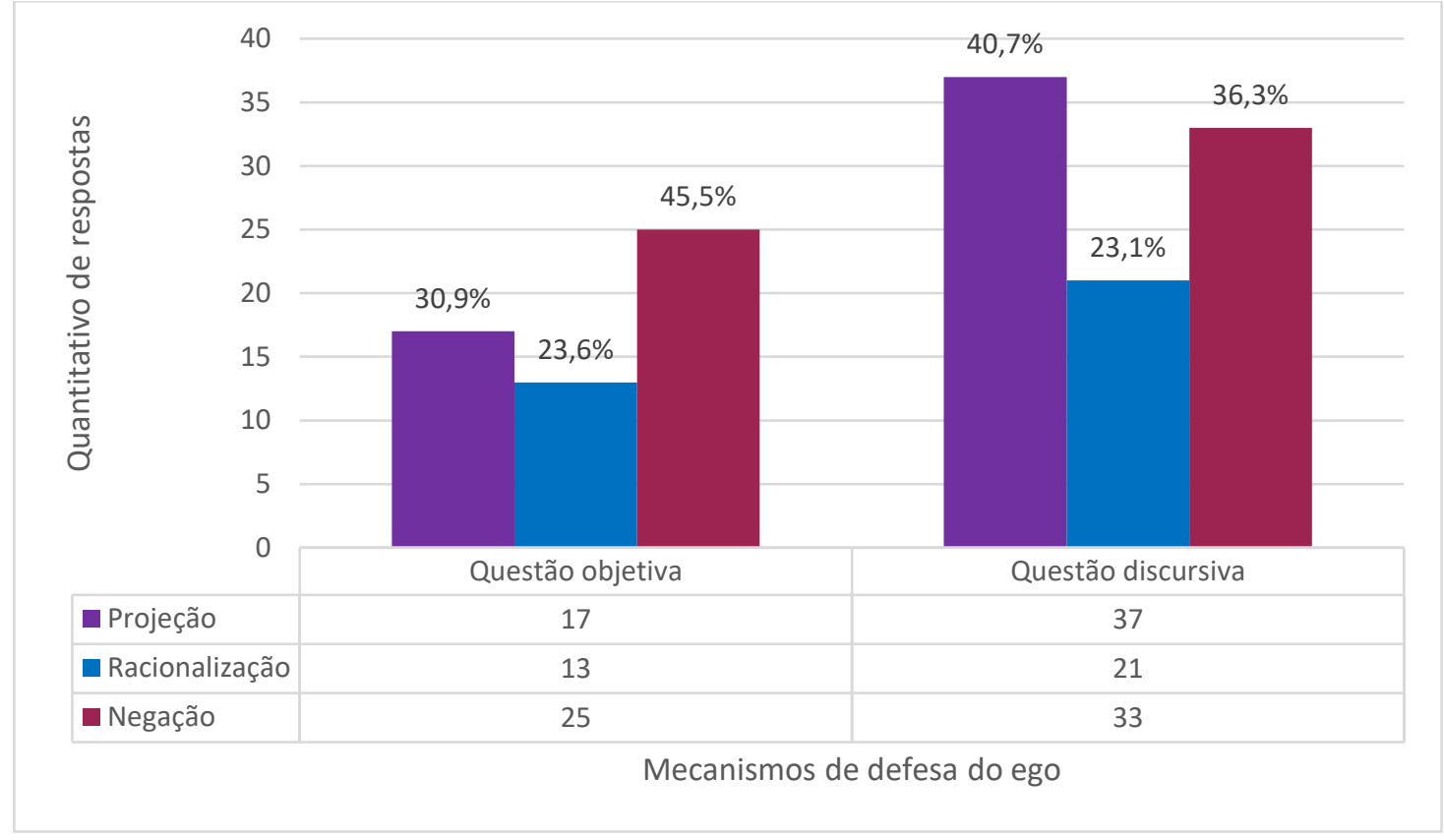

Observa-se que há maior prevalência dos mecanismos de projeção e negação. Segundo Nadvorny (2006), num processo de dependência alcoólica, os mecanismos que os indivíduos tendem a demonstrar são os de negação, utilizado para a recusa da doença e, muitas vezes, acompanhado de hostilidade para com o meio que convive, já no mecanismo de racionalização, o indivíduo faz uso de justificativas para os comportamentos inaceitáveis. E por fim, o mecanismo de projeção, neste a pessoa tende a atribuir a culpa do seu comportamento a outras pessoas. Porém, o dependente alcoólico não está livre de usar inconscientemente outros mecanismos, a fim de se esquivar ou proteger sua integridade psicológica (Townsend, 2017).

Com a finalidade de identificar os principais mecanismos de defesa do ego, junto aos dependentes alcoólicos em tratamento, abordaram-se para essa temática as afirmações e os relatos acerca do consumo do álcool, estas sendo feitas aos participantes com uma 
questão objetiva e duas subjetivas. Isso permitiu a comparação dos resultados entre essas questões, averiguando se houve similaridade ou discrepância nas respostas, com isso dando maior significância ao estudo. A partir das alternativas formuladas, com embasamento teórico, foi possível identificar os mecanismos de defesa utilizados pelos alcoólatras e quantificá-los, de modo a verificar o mais empregado. Diante das questões subjetivas, denota-se que o mecanismo de projeção foi o mais utilizado pelos dependentes, decorrente o mecanismo de negação e o de racionalização. Porém na questão objetiva, o mecanismo mais prevalente foi o de negação, seguido de projeção e racionalização.

$\mathrm{Na}$ demonstração desses resultados, verificase há uma pequena diferença entre as respostas dos indivíduos. Isso se dá devido às objetivas serem de múltipla escolha e haver o direcionamento das alternativas, em contraste ao exposto, nas subjetivas o sujeito tinha a plena liberdade nas suas repostas, assim não se obtém uma igualdade entre os valores, mas sim uma similaridade. Percebe-se que o mecanismo de racionalização nas duas questões é o menos utilizado, e o de negação e o de projeção intercalam-se como os mais prevalentes.

Tabela 2: Mecanismos de defesa do ego identificados conforme questões objetivas com exemplos de justificativas.

\begin{tabular}{lcc}
\hline $\begin{array}{l}\text { Exemplos de } \\
\text { justificativas }\end{array}$ & $\begin{array}{l}\text { Mecanismo de defesa } \\
\text { do ego }\end{array}$ & $\begin{array}{c}\text { Total } \\
(\%)\end{array}$ \\
\hline $\begin{array}{l}\text { "Só fui ao bar beber, } \\
\text { porque fulano me } \\
\text { chamou." }\end{array}$ & Projeção & $30,9 \%$ \\
\hline $\begin{array}{l}\text { "Eu não sou viciado, } \\
\text { na hora que eu quiser } \\
\text { paro de beber." }\end{array}$ & Negação & $45,5 \%$ \\
$\begin{array}{l}\text { "Só passei no bar para } \\
\text { cumprimentar meus } \\
\text { amigos." }\end{array}$ & Racionalização & $23,6 \%$ \\
\hline
\end{tabular}

O mecanismo de negação foi avaliado em duas perguntas interligadas, remetendo a períodos diferentes. Primeiro houve uma indagação em relação ao reconhecimento da doença antes do tratamento, posteriormente a questão levantada foi em relação à aceitação do diagnóstico após início do tratamento. Os resultados do primeiro questionamento demonstram que ocorreu maior quantitativo de indivíduos negando a doença, sendo esses valores invertidos em relação à condição atual, em que a maioria afirmou aceitar o diagnóstico. Entretanto, em consonância a isso, ainda percebe-se a prevalência de pessoas que não se conformaram em aceitar o etilismo como doença, predominando ainda, o mecanismo de negação, mesmo após a internação.

Medeiros (2019) explica em seus estudos que o uso do mecanismo de negação por indivíduos etilistas é uma forma de proteção por meio da rejeição da verdade, visto que está ligado a uma dificuldade em aceitar seus erros, falhas ou precariedades. De fato, o dependente alcoólico tende a negar sua condição ou até mesmo minimizá-la, de acordo com Videbeck 134 (2012), no entanto, o uso da negação retarda a busca por ajuda ou tratamento, condicionando assim ao agravamento da doença.

Tabela 3: Mecanismo de negação antes e depois do diagnóstico.

\begin{tabular}{lc}
\hline $\begin{array}{l}\text { Você se considerava dependente } \\
\text { alcóolico? }\end{array}$ & Total (\%) \\
\hline SIM & $26,7 \%$ \\
NÃO & $73,3 \%$ \\
\hline Aceita bem o diagnóstico? & Total (\%) \\
\hline SIM & $75,6 \%$ \\
NÃO & $24,4 \%$ \\
\hline
\end{tabular}

Muitos afirmaram, nas questões subjetivas, que o consumo de álcool dentro da família influenciou diretamente no seu vício. Mediante a isso, o esclarecimento para tal argumento frente aos mecanismos de defesa explica-se por meio do 
mecanismo de projeção, entretanto, conforme Filho et al. (2009) o autor Lev Vygotsky descreve que, muitas vezes, o meio onde a pessoa vive influencia diretamente em seu comportamento, fazendo ele reproduzir atitudes em que foi exposto durante o longo período de seu desenvolvimento psicológico. Diante disso, observa-se que existem duas formas de enxergar e analisar as alegações do dependente, e que elas têm um mesmo objetivo, trabalhar o psicológico desse dependente para que haja aceitação tanto de sua condição quanto do seu tratamento.

Em vista disso, nas respostas das questões subjetivas, a maioria dos indivíduos alegava que antes de sua internação, o etilismo não era reconhecido como doença, sempre afirmando que conseguiriam parar de beber no momento oportuno. Muitos dos dependentes argumentaram em suas respostas ter entrado nessa vida por influência familiar e outra parte das respostas era acompanhada da justificativa de seus atos. O que fica claro a utilização dos mecanismos de negação, de projeção e de racionalização, assim observando uma similaridade com os dados da questão objetiva. Com isso, fica melhor evidenciado nesta pesquisa, quais os mecanismos de defesa mais sobressaíram com as respostas dadas pelos dependentes do álcool internados no Instituto Crescer.

\section{CONCLUSÃO}

Por intermédio da apuração dos dados coletados, constata-se que nas questões sobre os mecanismos de defesa do ego os mais evidenciados foram o de negação, de racionalização e de projeção, logo, os dependentes utilizavam de tais mecanismos como uma forma de alegar seu vício. Contudo, outros autores demonstraram que o indivíduo reproduz o que ele vivencia em seu meio, sendo notório que nem todas as justificativas dadas pelas pessoas estão relacionadas ao uso de algum mecanismo do ego. De fato há necessidade de um trabalho psicológico com as pessoas em tratamento, a fim de que se possa libertálos para que haja aceitação, tanto de um tratamento quanto de sua condição.

Quanto aos problemas sociais, destacaram-se nesta pesquisa a família, o trabalho e a pobreza, assim havendo uma semelhança com outros estudos. Para um maior aprofundamento dos problemas sociais trabalhados, foram utilizadas questões direcionadas ao assunto, desse modo houve maior notoriedade nas alternativas que citavam: sentimento de vergonha por parte dos familiares; perda de oportunidades de trabalho devido à dependência; falta de dinheiro devido a gastos com a bebida; dificuldade de controlar o comportamento e dirigir sobre efeito de álcool. Em vista aos resultados obtidos com a amostra, percebe-se que é inevitável que a doença do dependente alcoólico não afete sua vida social, em que os problemas decorrentes não acometem somente sua saúde física, mas também sua saúde mental.

Em conformidade com os resultados 135 apresentados, com o que se encontrou na literatura, verifica-se que a dependência do álcool, por ser uma droga lícita e de fácil acesso, tornou-se um grande problema de saúde pública, sendo o estigma social, o fator mais agravante. Com a falta de conhecimento da população, o indivíduo passa a ser alvo de prejulgamento devido à sua doença, sendo muitas vezes intitulado com termos pejorativos como "bêbado". Assim sendo, forma-se uma resistência, até mesmo preconceito e vergonha da própria pessoa sobre sua condição, e este indivíduo passa a utilizar mecanismos de defesa do ego de forma inconsciente, porém prejudicial, como uma forma de justificar seu vício. Por meio da utilização dessas justificativas, há uma demora na busca do tratamento, devido ela não ser considerada uma doença por muitos.

Entre as limitações identificadas para o desenvolvimento do estudo, houve dificuldade de encontrar na literatura pesquisas acerca dos 
mecanismos de defesa atrelados ao etilismo. Ademais, é preciso que haja um esforço dos entes federados com os Conselhos de Saúde para atualização e efetivação das políticas públicas citadas e as existentes, conforme a demanda populacional atual. Bem como, mais incentivo financeiro por parte do Ministério da Saúde, para aplicação dos recursos em melhorias estruturais, mais contratação de profissionais especializados e maior abrangência da educação em saúde junto à população sobre o tema em discussão. Sendo esses recursos controlados e fiscalizados pelos Conselhos de Saúde, das três esferas de governo, garantindo a aplicabilidade deles onde se faz necessário. Dessa forma, possibilitando melhor entendimento e envolvimento da família e sociedade sobre o que é dependência química e seus agravos, uma vez que fica evidenciado que elas são palco, muitas vezes, das influências e dos prejuízos.

As ações em educação em saúde devem ter por objetivo a promoção e a prevenção de danos provocados pelo uso abusivo do álcool, não somente para evitar danos físicos, mas os danos psíquicos que têm sido assunto de grande preocupação na sociedade atual. Essas políticas também devem agregar as ações em saúde voltadas à recuperação dos indivíduos que se encontram enredados pelo vício, por meio da integralidade e da longitudinalidade do cuidado.

A pesquisa contém materiais que auxiliarão no campo técnico-científico de futuros estudos a respeito da temática, com a finalidade de aprimoramento atualização e efetivação de políticas públicas já existentes, visto que há uma ascendência do uso abusivo de álcool junto à população mundial, o que é considerado grande problema de saúde pública a ser combatido.

Todos os autores declararam não haver qualquer $\underline{\text { potencial conflito de interesses referente a este artigo. }}$

\section{REFERÊNCIAS}

ALMEIDA, N. D. Os Acidentes e Mortes no Trânsito Causados pelo Consumo de Álcool: um Problema de Saúde Pública. R. Dir. Sanit., São Paulo v.15 n.2, 2014.

ARAÚJO, W.S.C.; SILVA, A.F.S.; ESTRELA, F.M.; LÍRIO, J.G.S.; CRUZ, M.A.; SANTOS, J.R.L.; PEREIRA, A. A Influência do Consumo de Bebidas Alcoólicas na Ocorrência de Violência por Parceiro Íntimo: Revisão Integrativa. Arq. Cienc. Saúde UNIPAR, Umuarama, v. 22, n. 2, p. 117-122, maio/ago. 2018.

BRASIL. Ministério da Saúde. Portaria n⿳0 1.028, de $1^{\circ}$ de julho de 2005. Disponível em: <http://bvsms.saude.gov.br/bvs/saudelegis/gm/20 05/prt1028_01_07_2005.html>. Acesso em: 22 agos. 2020.

BRASIL. Ministério da Saúde. Portaria no 130, de 26 de janeiro de 2012. Disponível em: <https://bvsms.saude.gov.br/bvs/saudelegis/gm/2 012/prt0130_26_01_2012.html>. Acesso em: 20 agos. 2020.

BRASIL. Ministério da Saúde. Portaria no 3.588, de 21 de dezembro de 2017. Disponível em: <http://bvsms.saude.gov.br/bvs/saudelegis/gm/20 17/prt3588_22_12_2017.html>. Acesso em: 20 agos. 2020.

BRASIL. Ministério da Saúde. Portaria no 336, de 19 de fevereiro de 2002. Disponível em: <https://bvsms.saude.gov.br/bvs/saudelegis/gm/2 002/prt0336_19_02_2002.html>. Acesso em: 22 agos. 2020.

BRASIL. Presidência da República. Decreto $\mathbf{n}^{\mathbf{0}}$ 6.117, de 22 de maio de 2007. Disponìvel em: <http://www.planalto.gov.br/ccivil_03/_ato20072010/2007/decreto/d6117.htm>. Acesso em: 22 agos. 2020.

BRASIL. Presidência da República. Decreto $\mathbf{n}^{\mathbf{0}}$ 9.761, de 11 de abril de 2019. Disponível em: <https://www.planalto.gov.br/ccivil_03/_ato2019 -2022/2019/decreto/d9761.htm>. Acesso em: 19 agos. 2020.

BRASIL. Senado Federal. Projeto de Lei do Senado $N^{o} 83$ de 2012. Disponível em: <https://legis.senado.leg.br/sdleggetter/document 
$\underline{\mathrm{o} ? \mathrm{dm}=4645234 \& \mathrm{ts}=1567534386138 \& \text { dispositio }}$

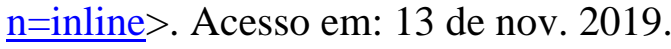

CARVALHO, D.A. Desafios da Saúde Mental na Atenção Básica. Monografia de Pós-graduação. Universidade Federal de Minas Gerais - UFMG; 2010.

CISA - Centro de Informações sobre Saúde e Álcool. Álcool e a Saúde dos Brasileiros: Panorama 2019. São Paulo: Centro de Informações Sobre Saúde e Álcool. Brasil, 2019.

FELIPPE, T. D. G. O Uso Abusivo de Álcool: em Servidores Militares Contribuição para Ciências do Cuidado. Niterói. Dissertação de Mestrado. Universidade Federal Fluminense - UFF; 2015.

FILHO, I. A. T. V; PONCE, R. F; ALMEIDA, S. H. V. As Compreensões do Humano para Skinner, Piaget, Vygotski e Wallon: Pequena Introdução às Teorias e suas Implicações na Escola. Psic. da Ed., São Paulo, 29, pp. 27-55 2009.

FREUD, A. O Ego e os Mecanismos de Defesa. Tradução Francisco Settíneri. Porto Alegre: Artmed, 2006.

LARANJEIRA, R.; MADRUGA, C. S.; PINSKY, I.; CAETANO, R.; MITSUHIRO, S. II Levantamento Nacional de Álcool e Drogas Consumo de Álcool no Brasil: Tendências entre 2006/2012. São Paulo: INPAD; 2013.

MALBERGIER, A.; ANDRADE, A.G.; SILVEIRA, C.M.; STORR, C.L.; BALTIERI, D.A.; CORTEZ, F.C.P.; ANDREUCCETTI, G.; GRINFELD, H.; ANTHONY, J.C.; PONCE, J.C.; ANDRADE, L.H.S.G.; CARDOSO, L.R.D.; OLIVEIRA, L.G.; VIANA, M.C.; AHLSTRÔM, S.; MARTINS, S. S.; HECKMANN, W.; LEYTON, V.; WANG, Y. Álcool e suas Consequências: Uma Abordagem Multiconceitual. 1.ed. São Paulo: Minha editora, 2009.

MEDEIROS, M. Mecanismos de Defesa da Mente. Managed, 2019

MELO, C., CAVALCANTE, I. A Codependência em Familiares de Adictos. Rev Fund Care Online, vol 11, 304-310, 2019.
MINAYO, M. C. S., NETO O. C., DESLANDES, S. F., GOMES, R. Pesquisa social: teoria, método e criatividade. $25^{\mathrm{a}}$ ed. Petrópolis-RJ: Vozes, 2007.

MONTEIRO, C.F.S.; DOURADO, G.O.L.; JUNIOR, C.A.G.G.; FREIRE, A.K.N. Mulheres em Uso Prejudicial de Bebidas Alcoólicas. Escola Anna Nery, 15 (3):567-572, 2011.

NADVORNY, B. Freud e as Dependências: Drogas, Jogo, Obesidade. 1 ed. Porto Alegre: AGE, 2006.

REINALDO, A. M. S., PILlON, S. C. Repercussões do Alcoolismo nas Relações Familiares: Estudo de Caso. Rev Latino-am Enfermagem, 2008.

RIBADIER, A; VARESCON, I. Study of Defender's Style, Defense and Copinho's Strategie i. Alcholic Addicted Population. Encephale. 43 (3): 223-228, 2017.

SILVA, M. I.; MANSINI, P. B.; CATELLI, T. Guia Prático de Saúde: Alcoolismo. 1 ed. São 137 Paulo: Eureka, 2015.

SILVA, V. X.; LUZ, H. H. V. As Implicações do Alcoolismo na Vida Social e Familiar do Indivíduo Dependente. Rio do Sul- SC, 2015.

TOWNSEND, M.C. Enfermagem Psiquiátrica: Conceitos de Cuidados na Prática Baseada em Evidências. Tradução de Denise Costa Rodrigues et al. 7 ed. Rio de Janeiro: Guanabara Koogan, 2017.

VIDEBECK, S.L. Enfermagem em Saúde Mental e Psiquiatria. 5 ed. Porto Alegre: Artmed, 2012.

WORLD HEALTH ORGANIZATION. Alcohol: Key Facts. 2018. Disponível em: <http://www.who.int/en/news-room/factsheets/detail/alcohol>. Acesso em: 12 out. 2018.

ZEMEL, M.L.S.; SADDI, L. Série O Que Fazer? Alcoolismo. 1 ed. São Paulo: Blucher, 2015. 